\title{
Filmando la vía chilena al socialismo: Estética de la contradicción en Compañero Presidente (Miguel Littín,
} 1971)

\section{Filming the Chilean Road to Socialism: Aesthetics of Contradiction in Compañero Presidente (Miguel Littín, 1971)}

José Miguel Palacios

New York University

jpd390@nyu.edu

Resumen El artículo se enfoca en las operaciones lingüísticas del documental de Miguel Littín, de modo de identificar una serie de dislocaciones relativas a la posición del hablante con respecto a la enunciación, donde la última es aquella del hablante como productor de discurso, que se desplaza desde la película hacia el espectador propiamente tal. En este documental, la consciencia del público es despertada a través de un proceso complejo de relaciones dialécticas que problematizan la realidad y la convierten en enunciaciones bajo la forma de contradicciones -aquello que denomino la estética de la contradicción y que constituye la principal estrategia discursiva de la película para convertirse en vehículo de producción de inteligibilidad social.

Palabras clave Revolución, Documental, Contradicción, Unidad Popular.

\begin{abstract}
The article focuses on the linguistic operations of Miguel Littin's documentary, in order to identify a series of dislocations regarding the position of the speaker in relation to the utterance, where the ultimate displacement is that of the speaker as the producer of discourse, which is transferred from the film to the viewer itself. The spectator's consciousness is awakened through a complex process of dialectical relations that problematize reality and turn it into a series of utterances in the form of contradictions - what I call an aesthetics of contradictions, which constitutes the documentary's main discursive strategy so as to become a vehicle for producing social intelligibility.
\end{abstract}

Key words Revolution, Documentary, Contradiction, Popular Unity. 


\section{Introducción}

La noche del 4 de Septiembre de 1970, las masas salieron a las calles de Chile a celebrar el triunfo de la Unidad Popular y su candidato Salvador Allende -el primer Marxista en el mundo convertido en presidente a través de elecciones democráticas. A lo largo del globo, los ojos de políticos, artistas e intelectuales, se volvieron hacia nuestro país pues desde aquí se planteó una noción diferente, si no única, de un proceso revolucionario, conocido como la Vía Chilena: una "revolución democrática" hacia el socialismo. En un libro reciente, Marcelo Casals ha argumentado que una de las principales características del periodo fue la presencia de elementos "ambiguos y contradictorios", debido a una diversidad de ideas inspiradas en el Marxismo y a un proceso de "creación colectiva” (2010: 13). Así, serían la originalidad y el cruce de sus planteamientos -y no sus objetivosaquello que hizo de la Unidad Popular un proceso "altamente" revolucionario (Ibíd..).

Si hemos comenzado con esta cita, no es porque nuestros objetivos sean los del historiador o aquellos del cientista político, sino más bien, porque en adelante nos referiremos a las conexiones entre los discursos políticos, ideológicos y estéticos, relación que descansa en un desplazamiento desde lo específicamente cinematográfico hacia los matices y particularidades de lo "político" y lo “ideológico" en el Chile gobernado por Allende, entendiendo lo político como el pensamiento y la acción de la UP y lo ideológico como el sistema de ideas y representaciones con el cual un grupo le da sentido al mundo que habita. Mientras Michael Chanan (1976:2) está convencido de que "casi la totalidad de la historia de la Unidad Popular puede rastrearse” a través de su cine, este artículo se escribe sobre la presunción inversa: que podemos comprender mejor el cine chileno del periodo desde y a través de la Unidad Popular. La inversión de la sentencia es significativa pues reconoce que estas películas no sólo "habitaron una zona politizada" (Burton, 1986: ix) o que "representaron un programa para una práctica política del cine" (Martin, 1977: 23), sino que se enfrentaron a una dialéctica permanente con una situación histórica-política particular: una revolución socialista dentro de las normas del orden constitucional.

Una de los ejemplos más emblemáticos de esta relación es el proyecto estético-fílmico de Miguel Littín, principalmente el Manifiesto de los Cineastas de la Unidad Popular (1970), su labor a la cabeza de la empresa estatal de producción Chilefilms, y el documental Compañero Presidente (1971)1. Tanto en el texto escrito como en la obra fílmica, se ponen en juego las ideas principales de un posible cine revolucionario para la Unidad Popular: un cine comprometido con "la

1 También podemos agregar el film de ficción La Tierra Prometida (1974), pero estudiarla en su complejidad escapa las posibilidades de este artículo. 
construcción del socialismo", que promovería una cultura nacional "auténtica”, y que movilizaría a sus espectadores a una "acción revolucionaria” (cit. en Mouesca, 1988: 71-2).

Pero así como la cualidad fundamental de la Unidad Popular radica en la originalidad de sus planteamientos, la verdadera subversión de este Manifiesto consiste en apuntar el blanco hacia sí mismo, hacia la propia idea de "lo revolucionario" que el documento intentaba desarrollar. La ontología de este cine es entonces una ontología de la negación, fundada sobre la base de una opción retórica que el manifiesto privilegia y que las películas que se inspirarían en él transformarían en una práctica estética: una estética de la contradicción. Para dicha estética, como he afirmado en otro lugar², lo revolucionario es "su capacidad para exponer una crítica en forma de contradicción -cuestionamiento a la vez que defensa de la revolución” (Palacios, 2011:9).

El análisis de Compañero Presidente que a continuación se presenta, ese preocupa, siguiendo a Collin MacCabe, de la producción de "una cierta realidad" la realidad socio-política del Chile de la UP- a través de "una serie de discursos contradictorios transformados por prácticas específicas” (1976: 11). Haremos un estudio de tipo lingüístico de modo de analizar la operación de esta estética de la contradicción en el discurso fílmico, enfocándonos no sólo en la enunciación propiamente tal, sino también en la posición del hablante (quién y desde dónde habla) en relación con dicha enunciación. Para MacCabe, con el discurso "nos interesamos en la relación dialéctica entre hablante y lenguaje, en la que el lenguaje ofrece siempre una posición hacia el espectador, y sin embargo, al mismo tiempo, el acto de hablar puede por sí mismo desplazar dichas posiciones" (12). Compañero Presidente ofrece varios ejemplos de tales desplazamientos, y es a través del estudio de estas dislocaciones que la estética de la contradicción del proyecto de cine revolucionario chileno se volverá claras.

\section{La dialéctica de Compañero Presidente}

El trabajo de Miguel Littín como presidente de Chilefilms ha sido ampliamente discutido en la historiografía del cine nacional (véase, entre otros, Parra, 1983; Mouesca, 1988; y Barría, 2011). No es necesario adentrarnos en dicha labor, pero sí conviene recordar que Littín fue designado en su cargo por Allende, y que el documental en cuestión sería a la postre el único largometraje producido enteramente por Chilefilms durante el periodo de la Unidad Popular. Estamos, en

\footnotetext{
2 Las ideas que se expondrán aquí sobre el manifiesto están extraídas de la ponencia "La contradicción como figura retórica en el Manifiesto de los Cineastas de la Unidad Popular", presentada en el Primer Encuentro de Investigación de Cine Chileno, organizado por la Cineteca Nacional en junio de 2011.
} 
consecuencia, ante un caso que obliga a pensar la obra más allá de sus aspectos formales, y a considerarla en su naturaleza institucional. El Compañero Presidente de Chilefilms se acerca prácticamente en su totalidad, al menos en sus intenciones, a lo que el teórico Teshome Gabriel ha denominado la tercera fase del Tercer Cine, la fase "combativa", donde "la industria no es sólo de propiedad del estado, sino que es manejada por y para el pueblo" (1989: 33). De ahí radica la peculiaridad de Compañero Presidente, un documental hecho a los pocos meses de asumido el gobierno de la UP, dirigido por el presidente de la compañía de producción fílmica estatal, y que presenta una larga entrevista al presidente de la nación, Salvador Allende, conducida por uno de los intelectuales de izquierda más célebres de la época, el francés Régis Debray.

Compañero Presidente está estructurado alrededor de dicha entrevista. Su forma cinematográfica da cuenta de la importancia para la narrativa de la banda de sonido: estamos en presencia, en última instancia, de una conversación intelectual entre dos individuos y son sus palabras lo que importa. La cámara no filma este diálogo a la manera convencional del plano/contra-plano, sino que en largas tomas que parecen responder a un doble propósito: 1) resolver una limitación tecnológica (hay sólo una cámara, por lo que ésta debe registrar permanentemente hasta agotar el material fílmico), y 2), evitar el corte de manera de ser "transparente" hacia la conversación y permitirle a esta última proveer el ritmo de la película (el rechazo del corte provoca la impresión de que es el diálogo en sí, la capacidad de seguir la conversación fácilmente, aquello que produce el montaje). Sin embargo, esta puesta en escena se traduce en una cámara en mano que está en constante movimiento (paneando desde el entrevistador al entrevistado y viceversa, rodeándolos, buscando una posición "sobre el hombro" [over the shoulder shot], acercándose y alejándose con el zoom, etc.) que produce todo excepto "transparencia”. Por el contrario, la cámara se hace visible. Esto sucede en sentido literal (cuando se hace zoom se ve en repetidas ocasiones al operador de sonido y a asistentes dando instrucciones) y en sentido formal (la visibilidad del dispositivo produce el reconocimiento de que estamos viendo una película).

No obstante, en Compañero Presidente esto tiene muy poco que ver con Brecht y el efecto de distanciamiento; no hay verdad escondida que se descubre mediante este procedimiento (la auto-reflexividad del aparato cinematográfico) pues no hay, hasta este punto en el documental, crítica alguna a lo que sucede en el nivel pro-fílmico. Se puede deducir entonces que esta puesta en escena responde a una limitación técnica, lo que se relaciona con la noción de "cine imperfecto" de Julio García Espinosa. Pero aquella sería una lectura miope del cineasta y crítico cubano, sustentada sólo en la ampliamente difundida cita de que el cine imperfecto "no está interesado en la calidad ni la técnica” (García Espinosa, 1983: 33). García 
Espinosa argumenta algo más complejo: un cine de lucidez que encuentra su expresión en aquellos que luchan -el pueblo lúcido- y un cine determinado a “mostrar el proceso de los problemas" (32). Mostrar no es analizar, pues lo último involucra un juicio de valor. "Mostrar el proceso de un problema, por el contrario, es someterlo a juicio sin pronunciar el veredicto” (Ibíd..). Por eso una película como ésta no es otra cosa que el registro, la fijación en material fílmico, del diálogo entre lo político, lo ideológico y lo estético. Sin embargo, una mirada más cercana a la manera en que este diálogo se produce probará que Compañero Presidente es muchísimo más problemática en su intento por ser un modelo de cine revolucionario.

Los dispositivos discutidos hasta el momento se refieren sólo a la mitad del documental, puesto que éste agrega una contra-narrativa con una forma cinematográfica propia. Por tanto, una oposición dialéctica entre la entrevista y estas secuencias estructura el film como un todo, a lo que denominaré el primer nivel de dialéctica dentro del documental. Distribuida a lo largo de la película, esta narrativa presenta la voz over de Debray -comentando sus impresiones personales sobre Chile- en secuencias donde las tomas de su llegada al país y su viaje en auto hasta la casa de Allende son yuxtapuestas con material de archivo sobre una variedad de tópicos y personas. Estas secuencias se organizan mediante una oposición dialéctica entre la imagen y el sonido, lo que denominaré el segundo nivel de dialéctica. Finalmente, existe un tercer nivel, referido al montaje dialéctico dentro de cada secuencia, una oposición que confronta cada toma a la anterior, y a partir de la cual es posible extraer una síntesis.

Una de estas secuencias sucede temprano en la película, cuando Allende contesta una pregunta sobre su educación marxista. La película corta de un plano medio del presidente a un paneo al interior de un auto (yendo desde el paisaje a la izquierda hacia Debray en el asiento de copiloto, visto de espaldas, y luego al paisaje a la derecha), justo en el momento en que el presidente dice que, en su juventud, solía leer en voz alta El Capital junto a otros estudiantes de medicina. La película corta nuevamente a un plano medio de Allende, quien dice: "Yo sé que no hay acción revolucionaria sin teoría revolucionaria; pero, esencialmente, yo he sido un hombre que he actuado". Lo que sigue es un montaje de 12 tomas, muchas ellas de duración inferior a un segundo, sobre la cual se escucha a Debray decir: "el gobierno popular, creo que es la expresión y el producto histórico de este desarrollo, tan especial y chileno, que ha combinado las formas políticas de la democracia burguesa con un amplio movimiento social proletario". Las doce tomas de la secuencia (a lo largo de la cual se escucha una música perturbadora, sin armonía ni tonalidad clásica) son las siguientes: 
1. Plano general de un grupo de personas que caminan en dirección a la posición de cámara. Uno de ellos lleva una bandera chilena.

2. Plano medio de un carabinero visto de espaldas, y paneo rápido a la izquierda, desde donde aparece el grupo anterior de gente.

3. Plano medio de un letrero que no se alcanza a leer, junto a una bandera chilena. La cámara se inclina hacia abajo y vemos a la gente esperando afuera de una casa.

4. Plano frontal de Allende haciendo un discurso dentro de la casa.

5. Contraplano: vemos la espalda de Allende, gesticulando y el pueblo escuchándolo. El teleobjetivo acerca la distancia entre ambos.

6. Plano general de carabineros montados a caballo.

7. Plano medio de la cara de un hombre que mira a los carabineros.

8. Un bus avanza hacia la posición de cámara.

9. Primer plano de un trabajador.

10. Contraplano: las espaldas de un grupo de tres a cuatro hombres, $y$, al fondo, los carabineros a caballo.

11. Primer plano de otro trabajador.

12. Primer plano de otro trabajador.

El espacio imaginario creado aquí ha sido diseñado como un campo de batalla: de un lado, el pueblo como un grupo organizado, consciente de sus símbolos nacionales, militante y disciplinado - en otras palabras, partícipe activo del proceso histórico en desarrollo-; del otro, las "formas de la democracia burguesa" representadas por las fuerzas represoras del Estado, que aparecen vigilantes pero sin interferir directamente con el pueblo. En medio de ambas, el presidente opera como mediador puesto que representa a las dos simultáneamente. Pero la película es cuidadosa en permitir dos tomas (n4 y 5) que lo sitúan, sin dudas, con el pueblo. Esta es una doble respuesta a las palabras de Allende sobre la acción. El film lo muestra como un político "activo", inmerso entre su pueblo; al mismo tiempo en que el pueblo observa atentamente la vigilancia distante de la policía, lista para reaccionar si esta última actúa primero.

Pero, antes de avanzar, es necesario considerar algo que, problemáticamente, hemos dado por hecho. Se ha usado "la película" como si ésta fuese una sola entidad que produce el discurso, cuando en efecto hay diferentes hablantes (enunciadores) aquí. MacCabe (17) se refiere al trabajo de Émile Beneviste para enfatizar la necesidad de distinguir entre el sujeto de la enunciación 
[le sujet de l'énonciation] (el hablante como productor de la cadena discursiva) y el sujeto del enunciado [le sujet de lénoncé] (el hablante como sujeto gramatical). Esta distinción es crucial tanto para el fragmento en discusión (el segundo y tercer nivel de dialéctica) como para la película como un todo (el primer nivel), pues hay distintas voces que operan como hablantes a lo largo del metraje. Atendiendo a esta escisión entre enunciación [utterance] y enunciado [statement], podemos evitar el peligro, en palabras de John Mowitt, de considerar la enunciación como aquello "que se refiere a sí misma como si viniese de la nada" (2005: 17). De acuerdo al teórico de la narrativa André Gaudreault, este es el mismo problema al que se enfrentó Gérard Genette al descubrir que, en ciertas ocasiones, las narrativas textuales pueden presentarse ante el lector sin la ayuda aparente de un narrador explícito e identificado como tal (Gaudreault, 2009: 64), problema que solucionó llenando ese vacío con la figura del autor. Para Gaudreault, este es un camino que debemos evitar, pues en el cine, la mayor parte de las veces las narrativas se desarrollan sin la mediación explícita de un narrador identificado como tal.

Conviene tener en cuenta la advertencia de Gaudreault, pues es fácil caer en la tentación de hablar del autor en lugar del narrador en Compañero Presidente. Notemos que la primera imagen del film identifica a su autor como "los trabajadores de Chilefilms", y por tanto, como un colectivo o multiplicidad de voces. Sin embargo, en los créditos finales, el director es claramente identificado como Miguel Littín. Como hemos visto, esto no convierte al autor/los autores en los sujetos gramaticales ni en los productores de la cadena discursiva; no obstante, esta multiplicidad de voces problematiza el proceso de enunciación en un paso más allá, especialmente si consideramos que es legítimo concluir que el objetivo final del film es presentar el pensamiento propio de Allende. Por consiguiente, podríamos estar tentados de argumentar que durante una buena porción del documental -la entrevista propiamente tal- Allende es el sujeto gramatical e incluso el productor de sentido, ya que el discurso del film está allí para apoyar al del presidente. Esto último, que sería lo lógico para cualquier obra de esta naturaleza (un documental producido por la compañía estatal de un país socialista, que presenta una entrevista a su presidente) no es el caso aquí.

La pregunta que debemos formular, entonces, siguiendo a Gaudreault, es más compleja que ¿Quién habla? La pregunta por el proceso de enunciación es: " ¿Quién, de los varios agentes narrativos, está hablando en este preciso momento de la narrativa?” (Gaudreault, 2009: 64).

En la secuencia analizada anteriormente, el sujeto gramatical no es identificable con claridad. Podemos argumentar que la voz de este pasaje, el yo de Debray, es lo que constituye el sujeto del enunciado. La clave aquí no es la voz over 
como dispositivo narrativo, sino la interjección explícita de Debray: "creo que"3. ¿Qué cree el intelectual francés? Que este es un sistema político definido por la combinación entre una democracia burguesa y un movimiento proletario. Ignoramos si esta voz over fue extraída de su entrevista a Allende (aunque su función como comentario político sugiere lo contrario), si proviene de algún escrito previo de Debray sobre el tema, o si fue grabada y añadida específicamente durante la edición. Lo que sí sabemos es que su voz no fue editada para acompañar las imágenes; fue editada contra ellas.

Debray no es el único hablante de esta secuencia y la pregunta de quién constituye el segundo es elusiva, puesto que, como se mencionó más arriba, estas secuencias pertenecen a una diégesis secundaria ${ }^{4}$. Pero definir quién es el hablante aquí es menos importante que comprender que el segundo nivel de dialéctica de la película (la oposición imagen/sonido) es lo que permite la emergencia del sujeto de la enunciación -el hablante como productor de discurso. Sin embargo, argumentaremos que en Compañero Presidente este enunciador ha sido desplazado hacia el espectador, pues sólo éste puede derivar una síntesis de la dialéctica de tres niveles propuesta; por tanto, el espectador no sólo descifra significados, sino que en definitiva los produce. Finalmente, aquí está el sentido de la sentencia de García Espinosa acerca de mostrar el proceso de los problemas para dejar el veredicto a su público, y la noción del argentino Fernando Birri de un espectador activo, quien, después de ver el film, retorna a la realidad para transformarla. Este desplazamiento es también el del Manifiesto de los Cineastas de la UP, que busca transferir el poder de la creación artística -es decir, la capacidad de producir un discurso revolucionario- a sus espectadores, y por ende, vaciar su posición como hablantes (en ambos sentidos) y disolverse en el rol de mero instrumento al servicio de la capacidad del pueblo de convertirse en su propio sujeto del enunciado/enunciación.

A esta altura, Compañero Presidente está ciertamente operando de manera Brechtiana. Para Tomás Gutiérrez Alea, el efecto de distanciamiento buscaba "sustituir una emoción cualquiera por la emoción específica de descubrir algo, de encontrar una verdad que había sido oscurecida en su cotidianeidad” (1983: 57). Posee, en consecuencia, una función ideológica. En la secuencia analizada, el espectador es forzado a concluir que lo que ha visto no es otra cosa que la puesta

\footnotetext{
3 Gaudreault nos dice: "Yo, en virtud de su auto-reflexividad, solo puede referirse a la propia persona que lo enuncia" (2009: 56).

4 Es en ejemplos de este tipo donde se visibiliza cierta inconveniencia en la aplicación de la lingüística al cine, como advierte Noël Carrol en su libro Mystifying Movies. Según Mowitt, el argumento principal de Carrol radica en que "para el concepto de enunciación es clave el concepto gramatical de persona, y claramente el cine (excluyendo diálogos y textos) carece de tal noción" (Mowitt, 2005, 17).
} 
cinematográfica de la lucha de clases. Más aún, la síntesis derivada de la oposición de las imágenes y la banda de sonido conlleva el descubrimiento de que este proceso chileno, pacífico, democrático y "tan especial”, sólo puede llevar a (y llevará a) un enfrentamiento armado.

Inmediatamente después de las tomas en las que detuvimos el análisis, la música cambia a una elegía. La voz over de Debray termina, al igual que el segundo nivel de dialéctica, pues ahora las imágenes apoyan el tono funerario de la música. Vemos un plano general de un amplio grupo de gente, tomados de la mano; luego, dos planos medios de personas cargando un ataúd y otros llevando una bandera chilena; el primer plano de una mujer que llora (en cámara lenta); hombres despidiendo una caravana de cinco ataúdes (con las banderas cubriéndolos); otro primer plano de una mujer llorando desesperadamente; un plano general (donde se aprecian las multitudes asistentes al funeral) que se inclina hasta un plano medio en cámara lenta de un hombre que le habla y gesticula a Allende, quien escucha pasivamente; $y$ una toma final donde la multitud se toma las manos.

El tercer nivel de dialéctica también está ausente aquí, ya que las tomas no se yuxtaponen en oposición unas a otras, sino que en un montaje que permite la continuidad narrativa del evento -el funeral-. Sin embargo, esta segunda parte de la secuencia está claramente opuesta dialécticamente a la primera, y una nueva síntesis puede ser derivada de esta relación. ¿Acaso el documental está argumentando que la originalidad del proceso chileno (mantener las formas de la democracia burguesa al mismo tiempo que promueve el crecimiento del poder popular) está destinada a la muerte, condenada al fracaso? Aquí, es relevante notar que Debray ya no es un hablante gramatical, de modo que esta sentencia no podría serle atribuida; por el contrario, se limita el rol del filósofo francés al de un articulador de una proposición intelectual y teórica. En consecuencia, nos queda "la película" tanto como sujeto del enunciado como de la enunciación. ¿Quién habla entonces este preciso momento? Recordemos que "la película” es también Littín, los trabajadores de Chilefilms, y todos ellos son empleados del Estado y, por ende, depositarios de la Unidad Popular y del discurso político e ideológico de Allende.

Quizás ambos descubrimientos (que este proyecto revolucionario derivará inevitablemente en un enfrentamiento armado y que está destinado al fracaso) no parecen particularmente sorprendentes, pero lo son si consideramos, como mostraremos más abajo, cómo se plantean dichas declaraciones -cómo se enuncian - en la producción oficial del discurso político e ideológico de la UP. La contradicción radica aquí en que Compañero Presidente es, a su vez, nada más que la comunicación de dichos discursos al espectador bajo la voz de su articulador político (el hablante como productor de enunciaciones) y líder (el hablante como 
sujeto del enunciado). Por lo tanto, la película afirma al mismo tiempo que niega los propios principios que gobiernan la revolución que supuestamente promueve.

Sobre este punto, es necesaria una dislocación referida precisamente a la negación de aquello que en teoría se promueve. En un artículo aún inédito ${ }^{5}$ sobre el film rumano 4 Meses, 3 Semanas, y 2 Días, (Cristian Mungiu, 2006), Jane Gaines se apoya en las teorías de Étienne Balibar para discutir la contradicción, tanto en el Marxismo como en la película, para responder la pregunta “¿Dónde está el Marxismo en la teoría del melodrama?” (1). Una de las contradicciones discutidas por Balibar es la siguiente: [El movimiento histórico] "es capitalismo en la medida en que el capitalismo hace al socialismo inevitable, y, a la inversa, es también socialismo en la medida en que el socialismo resuelve las contradicciones del capitalismo" (cit. en Gaines: 6). Gaines se enfoca en el "en la medida en que" de Balibar, con el cual este último:

(... ) es capaz de retener la formulación original que mantiene la posibilidad del socialismo, pero con cualidades que harían una excepción para el socialismo que no resolvió dichas contradicciones. No quedamos con una respuesta, sino con la pregunta de cómo analizar un texto que representa un socialismo que contraviene los ideales del socialismo, un socialismo fallido [énfasis propio] (Ibíd.) ${ }^{6}$.

Si hemos permitido esta conexión extemporánea y arbitraria entre dos películas radicalmente diferentes, y entre dos momentos histórico-políticos distintos, es porque esta pregunta, cómo analizar un texto que representa un socialismo que contraviene los ideales del socialismo, es una que no podemos eludir. Pero, ¿es Compañero Presidente realmente una película que contraviene los ideales que supuestamente promueve?

\section{Cine/Ideología/Política}

Antes de transcurrida la mitad del documental, Debray plantea una pregunta dirigida hacia el corazón de la teoría y práctica del socialismo de la Unidad Popular:

Con usted en el gobierno, el pueblo chileno ha escogido la vía de la revolución. Pero, zqué es revolución? Es sustitución del poder de una clase por otra. Revolución es destrucción del aparato burgués y su reemplazo por

\footnotetext{
5 Artículo facilitado personalmente por la autora para esta investigación. Las citas que siguen incluyen número de páginas de acuerdo al documento enviado. No hay año de publicación.

6 La cita original en inglés dice: "(...) is able to retain the original formulation that holds out the possibility of socialism, but with qualifications which would make an exception of the socialism that did not resolve these contradictions. We are left not with an answer, however, but with the question of how to analyze the text that represents a socialism contravening the ideals of socialism, a failed socialism."
} 
otro. Y acá no ha pasado nada de eso. Entonces, ¿dónde estamos, Compañero?

La larga respuesta de Allende -que se resume brevemente en que el gobierno nunca ha olvidado "el principio fundamental del Marxismo: la lucha de clases" - es menos esclarecedora que el rastreo de las condiciones históricas que permiten que Debray plantee tal pregunta.

En su estudio de la izquierda chilena entre 1957 y 1973, Marcelo Casals propone la tesis de que ésta se dividía en dos grandes tendencias: una que denomina "sistémica”, agrupando a todos aquellos que veían en la participación institucional el camino adecuado hacia la revolución en Chile, y una "rupturista", incluyendo a quienes desarrollaron "planes de acción destinados a la destrucción del orden constitucional como la condición necesaria para la creación de un sistema socialista” (2010: 11). Casals argumenta que el programa político de la Unidad Popular fue el resultado de la mezcla de ambas tendencias más los aportes del pensamiento de Allende -lo que algunos llamaban Allendismo-. El Allendismo se situó en un punto intermedio, en constante tensión con las tendencias descritas. La originalidad de la Vía Chilena al socialismo se representa en esta relación, predispuesta naturalmente hacia la contradicción -tal como el Manifiesto-.

Esta predisposición ontológica es, como hemos visto con Balibar, Marxista en términos propios. Lawrence Crocker explica que para Marx, dos cosas son contradictorias si ambas son "procesos", tienen "caminos naturales de desarrollo", y si estos caminos "no pueden realizarse conjuntamente" (1980: 560). Tal naturaleza paradójica puede apreciarse claramente en dos citas de Salvador Allende, una extraída de un discurso y la otra de una entrevista televisiva, -ambas para la campaña presidencial de 1964 que Allende terminó perdiendo. En el discurso, luego de reconocer la vía legal/electoral como la escogida para alcanzar el poder, el candidato afirma: "(...) a quienes empleen la violencia, vamos a contestarles con la dura, la tremenda, con la decisiva violencia del pueblo, que es violencia multitudinaria” (Allende, 1964: 14). En la entrevista televisiva, sin embargo, Allende explicaría la naturaleza de su gobierno en términos distintos:

¿Usted cree que en Chile vamos a establecer un gobierno de corte marxista? Yo le digo que no! (...) Queremos un gobierno democrático, nacional, popular y revolucionario. Una etapa de transición entre el régimen capitalista $(\ldots)$ y el que pueda venir en el futuro, que para mí será el socialismo. Pero el socialismo no se impone por decreto ( ... ). No se puede establecer mañana un país socialista por la voluntad de un gobernante" (cit. en Casals, 2010: 117).

En la primera cita, es evidente, tal como destaca Casals, la contradicción y tensión teórica entre el respeto por el orden legal vigente y la posibilidad de 
desencadenar un proceso violento. Si seguimos a Marx, estos procesos son contradictorios pues una vía revolucionaria fundada en el respeto hacia el orden constitucional y una que fomenta el desarrollo del "poder popular" nunca convergirían. Vemos, entonces, que no sólo la retórica del discurso político (ejemplificada por Allende) y aquella del discurso estético (ejemplificada por el manifiesto) son similares, sino que a su vez nacen del mismo principio de contradicción. Lo que en otro lugar ${ }^{7}$ hemos denominado como retórica de la convergencia al discutir el Manifiesto de los cineastas de la UP, es decir, la idea implícita de que la lucha -artística/estética, política- se dirige simultáneamente en diferentes direcciones con la convicción de que coincidan en algún punto -el momento en que se consiguen tanto la liberación, como la cultura nacional “auténtica”, como la revolución-, se vuelve una imposibilidad desde un principio.

Dos ironías derivan de este razonamiento. La primera es que esta imposibilidad fue sabida y asumida desde un principio por Littín - - Cómo, si no, interpretar el llamado del manifiesto a "desarrollar nuestras propias contradicciones"?-. La segunda es que, al intentar escapar del camino "ortodoxo" hacia el socialismo y en su insistencia por crear uno propio que respondiese a las necesidades de Chile, Allende se acercó más al Marxismo, al menos en sus fundamentos referidos a la contradicción. Esto puede verse en la cita de la entrevista televisiva, que dialoga directamente con la pregunta de Debray en la película acerca de la naturaleza revolucionaria de la UP. En el fragmento citado, el discurso político niega su proveniencia ideológica al mismo tiempo que la reafirma: ¿Qué, si no socialismo, es la suma de "democrático, nacional, popular y revolucionario"?

La contradicción descansa, por consiguiente, en el corazón del discurso estético del manifiesto, en el discurso fílmico de Compañero Presidente, y en el discurso político de Allende en su interpretación del discurso ideológico Marxista. No conviene, por el momento, seguir empujando esta retórica de ontologías paradójicas -tal camino nos llevaría a una calle sin salida o a una tautología-, pero es relevante enfatizar que son estas contradicciones las que permiten la emergencia de un espectador activo, y por ende, de una potencial acción revolucionaria del espectador.

Conceptos similares a los que Littín buscaba aplicar a su práctica cinematográfica, fueron desarrollados en 1983 por Tomás Gutiérrez Alea en su clásico libro La dialéctica del espectador. En él, el cineasta cubano explora la relación entre espectáculo y espectador, ensayando una respuesta a la pregunta de qué constituye la "toma de consciencia" (22) del espectador, y qué sucede cuando éste regresa (luego de abandonar la sala de cine) a enfrentarse a su realidad y vida social

7 Ver la ponencia citada en la nota al pie $n^{\circ} 1$ 
cotidiana. Se interesa, por tanto, no en cualquier espectáculo, sino en aquél que denomina un espectáculo "socialmente productivo" (Ibíd..). Ve este último como una "mediación" de la realidad, que corresponde al "momento de abstracción en el proceso de entendimiento” (41). Hemos mencionado previamente cuán importante es dicho proceso para el descubrimiento de la "verdad oculta", a la manera de Brecht. Pero la mayor contribución de Gutiérrez Alea -y una que dialoga directamente con Compañero Presidente- no es su apropiación de Brecht para el discurso estético de la revolución cubana, sino su conclusión de que una realidad mediada por un espectáculo socialmente productivo debe ser problematizada en/por el espectador para provocar una respuesta en él. En consecuencia, Gutiérrez Alea argumenta que dicho espectáculo es aquel que "niega la realidad diaria ... al mismo tiempo que siente las premisas de su propia negación. Esto es, niega ser un sustituto de la realidad y un objeto de contemplación" (44).

Compañero Presidente, como hemos visto en el análisis, niega la realidad que nos muestra -y por realidad me refiero aquí al resultado de la conexión de estos discursos contradictiorios- al mismo tiempo que "muestra el proceso" de su negación. Del manifiesto de los cineastas de la UP, hemos afirmado que buscaba deliberadamente significados equívocos, al contrario de lo que Robert Stam ha observado en relación al "modelo" de cine documental revolucionario en América Latina, La hora de los hornos (Fernando Solanas y Octavio Getino, 1968), donde los mensajes son claramente inequívocos. Stam está sin duda en lo correcto cuando considera la naturaleza paradójica de las nociones de apertura y ambigüedad en la película argentina; pero su idea no se aplica en Compañero Presidente, donde apertura no significa "plurisignificación" ni se refiere a la multiplicidad de lecturas posibles de una obra artística, sino a esa compleja polisemia de un discurso político contradictorio - negado en virtud de su afirmación-.

La última secuencia de la película es un claro ejemplo. Debray y Allende conversan en Valparaíso, con el mar como telón de fondo, y el presidente cierra sus palabras afirmando:

Algún día América tendrá una voz de continente, de pueblo unido (...), dueño de su propio destino. Esto es lo que yo pienso, Régis, y creo que tú (... ) nos puedes ayudar mucho, diciendo lo que has visto y diciendo lo que queremos.

Inmediatamente después de las últimas palabras de Allende, el himno de la Unidad Popular, la canción Venceremos, empieza a escucharse en la banda sonora, pero sólo por breves segundos. Su volumen disminuye gradualmente hasta desaparecer. Luego, el último momento dialéctico de la película. Escuchamos a las masas gritando “;Allende, Allende!”, y la voz over de Debray, quien dice: "Es muy chileno lo que aquí ha ocurrido. Chileno también es el lema que está en el escudo 
nacional: por la razón o la fuerza. Aparentemente, hasta hoy, todo ha sido por la razón. ¿̇Hasta cuándo?”.

Durante el comentario de Debray, vemos varias tomas, muy cortas, de las masas ( siempre ondeando una bandera chilena), yuxtapuestas a la misma toma anterior de Allende y Debray frente al mar, que ahora panea hacia la izquierda hasta encuadrar sólo el mar. Este movimiento no es fluido, puesto que se interrumpe cada vez para dar lugar a la inserción de las tomas donde se ve el pueblo. Cuando la voz de Debray calla, el himno vuelve a aparecer en un alto volumen. Sobre una toma congelada de la última imagen de las masas, se sobreimprimen los principales logros del gobierno de Allende, coincidiendo su final con el de la canción y la película.

Cuando Debray se pregunta “'hasta cuándo?”, ¿se refiere a que es el pueblo el que deberá armarse para llevar su revolución hasta las últimas consecuencias, o a que una contra revolución militar terminará por la fuerza el proceso? ¿O acaso se refiere a ambas posibilidades? Como no podemos estar seguros, los significados derivados de este pasaje no son sólo múltiples, sino que principalmente equívocos. Parecen más equívocos aún si volvemos a la pregunta lingüística, pues ignoramos si esta es una sentencia que la película asume como propia, o si la limita sólo a Debray en su condición de sujeto gramatical y no como el productor del discurso final. Por lo demás, el llamado del presidente al intelectual a que "cuente lo que ha visto", abre la posibilidad de interpretar el documental como el mensaje de Debray al mundo. Podemos tomar como clave que la canción aparece solamente después del razonamiento de Debray, no lo acompaña. Puesto que vemos los logros del gobierno mientras escuchamos el himno -creado para celebrar el triunfo de Allende y para promover el conocimiento de su programa-, se colige que el film argumenta que sólo a través de la profundización de las transformaciones sociales en desarrollo, lograrán los objetivos de la revolución, objetivos que Allende repite en su intervención final: independencia política y económica. Por consiguiente, la película parece desprenderse de la proposición final de Debray. Sin embargo, si el significado de tal declaración no está claro, ¿cómo podemos saber de qué se desprende Compañero Presidente, y qué es lo que afirma?

\section{Conclusión}

Enfocarnos en las operaciones lingüísticas del documental de Miguel Littín, nos ha permitido identificar una serie de dislocaciones relativas a la posición del hablante con respecto a la enunciación, donde la última es aquella del hablante como productor de discurso -y, por ende, de sentido-, que se desplaza desde la película hacia el espectador propiamente tal. La consciencia del espectador es despertada a través de un proceso complejo de relaciones dialécticas que problematizan la realidad y la convierten en enunciaciones bajo la forma de 
contradicciones -aquello que denomino la estética de la contradicción-. Mostrar dicho proceso permite el surgimiento de un espectador "activo", pues es éste quien "siente la emoción” de descubrir las verdades ocultas propuestas en el film.

Sin embargo, aquí enfrentamos un problema. Hemos visto cómo el manifiesto entiende el cine revolucionario como ese cine que sólo deviene revolucionario una vez que haya movilizado a su público a una acción revolucionaria. Tal acción, pensamos, sólo podría ocurrir si la obra ha transferido al espectador, exitosamente, su capacidad de producir discurso y sentido. No obstante, dicha capacidad es negada en la medida en que Compañero Presidente permite una polisemia de mensajes políticos que no sólo son distintos y variados, sino también, equívocos y contradictorios. Tomás Gutiérrez Alea, por el contrario, argumenta que un espectáculo socialmente productivo lanza a los espectadores a la calle "con sólo el camino indicado [mi énfasis], camino que deberán perseguir cuando cesen de ser espectadores y devengan actores de su propia vida” (1983: 61). Esto es totalmente lo opuesto de este documental chileno, que propone distintos caminos, y por tanto, ninguna vía única que pueda derivar en acción revolucionaria. Si esto es cierto, el cine revolucionario, tal como lo entiende Littín y lo practica aquí, es una imposibilidad (o, en el mejor de los casos, una realidad casi oximorónica).

¿Es esta una subversión original? ¿Acaso la negación ontológica de este cine revolucionario lo convierte en "más" revolucionario? O, por el contrario, es un cine demasiado confiado de la (supuesta) naturaleza vanguardista de su pueblo? Un cine que considera a su espectador tan consciente de su tiempo y lugar en la historia que está preparado no sólo para descifrar sino también para producir significados a partir de proposiciones contradictorias? ¿Se condena, a sí mismo y al proyecto revolucionario que apoya, al fracaso? ¿O está convencido de que su autoreflexividad con respecto a este fracaso revela de alguna manera una "verdad" escondida en lo más hondo?

Son preguntas que abren el debate hacia una investigación que promueva un diálogo entre las teorías sobre el espectador y qué significa el proceso de ser un espectador [spectatorship] con aquellas relativas a la clase y la noción de pueblo. Si bien estas preguntas prosiguen el énfasis en el devenir propuesto en el proyecto de Littín - películas que no son revolucionarias en sí, sino que devienen revolucionarias posteriormente-, en efecto lo llevan a terrenos y conclusiones que difieren de sus principios. No obstante es necesario seguir buscando respuestas a dichas interrogantes, del análisis textual podemos concluir una que es, también, insospechada. La cuestión del devenir es ilusoria, porque al transferir al espectador gran parte de la responsabilidad, si no toda, de la producción de discurso, la película se convierte en vehículo de producción de inteligibilidad social. Si la pregunta es cuándo sucede la acción revolucionaria, la respuesta es ahora. La inteligibilidad 
social no ocurre después de vista la película; ocurre durante su visionado. La acción revolucionaria que moviliza la obra no es otra que la de producir la obra propiamente tal.

\section{Referencias bibliográficas}

Allende, S. (1964). “Nuestra lucha es decisiva”. Arauco. No 50. pp. 13-14.

Barría, A. (2011). El espejo quebrado. Memorias del cine de Allende y la Unidad Popular. Santiago: Uqbar.

Birri, F. (1985). "For a Nationalist, Realist, Critical and Popular Cinema”. Trad. Michael Chanan. Screen. Vol. 26 n $^{\circ}$ 3-4. pp. 89-92.

Burton, J., ed. (1986). Cinema and Social Change in Latin America. Austin: University of Texas Press.

Casals, M. (2010). El alba de una revolución. Santiago: LOM Editores.

Chanan, M., ed. (1976). Chilean Cinema. London: British Film Institute.

Crocker, L. (1980). "Marx's Use of Contradiction”. Philosophy and Phenomenological Research Vol. 40 n4.pp. 558-63.

Gabriel, T. (1989). “Towards a Critical Theory of Third World Films”. En Questions of Third Cinema. London: BFI. pp. 30-52.

Gaines, J. (sin año). "Four Months, Three Weeks and Two Days: Where is the Marxism in Melodrama Theory?". En Conference Proceedings "Rethinking Cinema/Repenser le cinéma". London: Peter Lang.

García Espinosa, J. (1983). "Por un cine imperfecto”. En Twenty-five years of the new Latin American cinema. London: British Film Institute.pp. 28-33.

Gutiérrez Alea, T. (1983). La dialéctica del espectador. México D.F.: Federación Editorial Mexicana.

Littin, M. (1988). "Manifiesto de los Cineastas de la Unidad Popular". En Plano secuencia de la memoria de Chile: veinticinco años de cine chileno (1960-1985). Madrid: Ediciones del Litoral.pp. 71-2.

MacCabe, C. (1976). “Theory and Film: Principles of Realism and Pleasure”. Screen. Vol. 17 no3.pp. 7-28.

Martin, M. T., ed. (1997). New Latin American Cinema Vol. 2. Detroit: Wayne State University Press.

Mowitt, J. (2005). Re-Takes: Postcoloniality \& Foreign Film Languages. Minnesota: University of Minnesota Press.

Palacios, J.M. (2011, 21-23 Junio). La contradicción como figura retórica en el manifiesto de los cineastas de la UP. Ponencia presentada en Primer Encuentro de Investigación de Cine Chileno. Santiago. 
Parra, I. (1983). “Conversación con Miguel Littin”. Araucaria de Chile. № 21.pp. 77-94.

Stam, R. (1990). "The Hour of the Furnaces and the Two Avant Gardes". En Social Documentary in Latin America. Pittsburgh: University of Pittsburgh Press. pp. 251265 .

\section{Referencias filmográficas}

Littín, M. (1971). Compañero Presidente. Chile: Chilefilms.

(1974). La Tierra Prometida. Chile/Cuba: Cinematográfica Tercer Mundo/ ICAIC.

Solanas, F. Y Getino, O. (1968). La hora de los hornos. Argentina: Grupo Cine Liberación. 